\title{
Making technological innovation work for sustainable development
}

Laura Diaz Anadon ${ }^{a, b, 1,2}$, Gabriel Chan ${ }^{c, 1}$, Alicia G. Harley ${ }^{a, 1}$, Kira Matus ${ }^{b}$, Suerie Moon ${ }^{a, d, 3,4}$, Sharmila L. Murthy ${ }^{e}$, and William C. Clark ${ }^{a}$

Edited by Louis Lebel, Chiang Mai University, Chiang Mai, Thailand, and accepted by Editorial Board Member Ruth S. DeFries July 13, 2016 (received for review December 17, 2015)

This paper presents insights and action proposals to better harness technological innovation for sustainable development. We begin with three key insights from scholarship and practice. First, technological innovation processes do not follow a set sequence but rather emerge from complex adaptive systems involving many actors and institutions operating simultaneously from local to global scales. Barriers arise at all stages of innovation, from the invention of a technology through its selection, production, adaptation, adoption, and retirement. Second, learning from past efforts to mobilize innovation for sustainable development can be greatly improved through structured cross-sectoral comparisons that recognize the socio-technical nature of innovation systems. Third, current institutions (rules, norms, and incentives) shaping technological innovation are often not aligned toward the goals of sustainable development because impoverished, marginalized, and unborn populations too often lack the economic and political power to shape innovation systems to meet their needs. However, these institutions can be reformed, and many actors have the power to do so through research, advocacy, training, convening, policymaking, and financing. We conclude with three practiceoriented recommendations to further realize the potential of innovation for sustainable development: (i) channels for regularized learning across domains of practice should be established; (ii) measures that systematically take into account the interests of underserved populations throughout the innovation process should be developed; and (iii) institutions should be reformed to reorient innovation systems toward sustainable development and ensure that all innovation stages and scales are considered at the outset.

sustainable development | innovation systems | technology | knowledge systems | complex adaptive systems

This paper sets forth our perspective on how technological innovation can better advance the goals of sustainable development. We seek to help bridge the gap between scholarship and practice by drawing from conceptual research, empirical cases, and realworld experience to highlight practical guidelines for use by practicing scientists, engineers, entrepreneurs, and policy advocates.

Sustainable development was defined a generation ago through a series of United Nations-led commissions and summits as development that "meets the needs of the present without compromising the ability of future generations to meet their own needs" (1). Subsequent work by scholars and international development organizations has broadened the original framing to define development as sustainable when "inclusive wellbeing"-the aggregate quality of life for all people, everywhere, now and in the future-does not decline with time (2-5). More recently, in September 2015, virtually all member countries of the United Nations committed to 17 Sustainable Development Goals (SDGs) that provide specific targets and timetables for enhancing inclusive well-being.

Technological innovation is at the heart of sustainable development. Innovation itself is one of the SDGs (goal 9) and also a means for achieving the others. Technology is the subset of knowledge that includes the full range of devices, methods, processes, and

\footnotetext{
aHarvard Kennedy School of Government, Harvard University, Cambridge, MA 02138; 'bepartment of Science, Technology, Engineering, and Public Policy, University College London, London W1T 6EY, United Kingdom; ' Humphrey School of Public Affairs, University of Minnesota, Minneapolis, MN 55455; 'Harvard T. H. Chan School of Public Health, Harvard University, Boston, MA 02115; and 'esuffolk University Law School, Suffolk University, Boston, MA 02108

Author contributions: L.D.A., G.C., A.G.H., K.M., S.M., S.L.M., and W.C.C. wrote the paper.

The authors declare no conflict of interest.

This article is a PNAS Direct Submission. L.L. is a Guest Editor invited by the Editorial Board.

${ }^{1}$ L.D.A., G.C., and A.G.H. contributed equally to this work.

${ }^{2}$ Address beginning September 2016: Department of Politics and International Studies, University of Cambridge, Cambridge CB3 9DT, United Kingdom.

${ }^{3}$ Address beginning October 2016: Global Health Centre, The Graduate Institute of International and Development Studies, 1202 Geneva, Switzerland.

${ }^{4}$ To whom correspondence should be addressed. Email: smoon@hsph.harvard.edu.

This article contains supporting information online at www.pnas.org/lookup/suppl/doi:10.1073/pnas.1525004113/-/DCSupplemental.
} 
practices that can be used "to fulfill certain human purposes in a specifiable and reproducible way," whereas innovation is the "process by which technology is conceived, developed, codified, and deployed" (6). The innovation process occurs in multifaceted "innovation systems," which can usefully be thought of as the connected set of actors and institutions that shape innovation processes $(7,8)$.

This paper focuses on how broad systemic change can be affected by practicing scientists, engineers, entrepreneurs, and policy advocates working on specific technologies or the rules and incentives governing technological innovation (e.g., scientists conducting early-stage research, donors selecting particular technologies for funding, or governments promoting technology cooperation). An approach to understanding the opportunities for this set of actors emerges from a multilevel characterization of innovation systems (9), as suggested in the following example. At any given moment, particular social goals (e.g., increasing availability of energy services) are addressed through a particular combination of technologies, rules, and actors, forming a "regime" (e.g., the dominant fossil fuel system). These regimes have, in turn, been shaped by the "landscape" of social trends and large spatial patterns (e.g., the geopolitics and economics of the oil industry). New technologies within regimes (e.g., high-efficiency wind turbines) are generally initially developed within local "niches" (9) of conducive practices and circumstances (e.g., local and regional markets with targeted policies to advance renewable technologies). Regimes are usually resistant to novelty developed in niches, but can sometimes be disrupted, resulting in the widespread use of new technologies, changes to actor behavior and institutions, and even the transition to a new regime (e.g., meeting energy goals through a fully renewable system).

The multilevel perspective focuses attention on how activities within niches may eventually lead to regime-level transitions. Although progress at the niche level will not be sufficient for bringing about sustainability transitions, such progress is surely necessary for any transition in the dominant regimes organizing production and consumption processes for the principal constituents of inclusive well-being (e.g., food, water, energy, health, housing, and so on). However, the activities needed beyond niches to accelerate sustainable development at a regime level remain poorly understood and a frontier of sustainability science research (10).

The factors impeding the mobilization of technological innovation for sustainable development are largely the same factors impeding innovation in general. However, there is also a particular challenge for those working to advance sustainable development: the impoverished, marginalized, and future populations that are a central concern of efforts to improve inclusive well-being too often lack the economic and political power to shape innovation systems to meet their needs. For example, global investment in research and development (R\&D) in medicines for "neglected diseases" is inadequate because the developing country populations who bear the primary burden of such diseases lack the means to incentivize such investment (11). Likewise, current investment in low-carbon energy does not fully reflect the interests of future generations who will be impacted by climate change because those unborn populations cannot directly influence current innovation systems (12).

Making innovation work for sustainable development in general, and for populations lacking power in particular, will require greater clarity in conceptualizing the innovation process itself, in identifying barriers to innovation, and in learning from a wealth of academic research and past experience. Many studies of innovation have focused on specific nations (8), sectors (13), or technologies (14).
Innovation scholars have also proposed several conceptual frameworks for understanding how technologies emerge, change, and are adopted $(8,13,15,16)$. However, this literature is seldom explicitly connected to the specific problems facing actors who seek to promote sustainable development $(17,18)$. In this paper, we draw three broad insights from scholarship and practice that together should help such practitioners design interventions to improve innovation for sustainable development:

i) Innovation systems are complex adaptive systems characterized by codependent innovation stages with multiple feedbacks, positive and negative ripple effects, and the potential for nonlinear impacts;

ii) Innovation systems are socio-technical systems shaped by the reciprocal interactions of social and technological factors; understanding innovation systems in this way enables more useful cross-sectoral learning; and

iii) Innovation systems are guided by institutions that too often reflect the goals of the powerful rather than those of impoverished, marginalized, and future populations; however, institutions can be reshaped by actors with various forms of power in ways that support innovation for sustainable development.

Throughout the paper, we use a common set of illustrative cases to make our arguments concrete. We selected these cases to reflect the range of challenges faced by actors seeking to harness innovation for sustainable development. They encompass technologies at different degrees of maturity that are both physical artifacts and nonphysical practices, activities in a range of geographic areas and governance scales, and interventions to address various sustainable development needs. Our illustrative cases are presented in detail in SI Text.

\section{Understanding Innovation as a Complex Adaptive System} Understanding how innovation systems work requires analyzing the actors and institutions that contribute to innovation in a particular geographic region (8), sector (13), technological area (15), or level of analysis (9). Actors typically include individuals and organizations operating at multiple scales (e.g., central governments, local authorities, universities, private firms, nonprofits, entrepreneurs, and technology users). Institutions include the set of formal and informal rules, norms, decision-making procedures, beliefs, incentives, and expectations that guide the interactions and behavior of actors in an innovation system (19-22). The connections among actors and institutions across the many stages of the innovation process, which occur in multiple sectors and at different scales, make innovation systems complex and adaptive.

Innovation involves multiple stages of activities that can be tightly linked, often overlap, and do not necessarily occur in a specific sequence. There are a number of different ways innovation systems and their constituent activities can be conceptualized (13, $15,23)$. For clarity of exposition, we have found it useful to group innovation activities into seven stages: invention (the process leading to the initial discovery of a technology), selection (the choice of a technology for a given setting), initial adoption (the early use of a selected technology in a specific context), production (the manufacturing of a technology), adaptation (efforts by users or inventors to modify a technology to better serve the needs of individual users), widespread use (the broad adoption of a technology in different communities of users), and retirement (the replacement of a technology by a new, more effective technology).

The types of activities that occur in different innovation stages often require distinct modes of thinking, the engagement of diverse 
actors across multiple scales-from individuals to multinational governance bodies (8), and the mobilization of many physical and intangible resources. Further, actors are embedded in social systems with complex sets of institutions that shape their behavior (24). Hence, emergent system-level "functions of innovation systems" arise from the actions of many actors across the set of interconnected innovation stages (15).

Innovation Stages Do Not Follow a Set Sequence. Activities in different innovation stages can occur in various sequences, unfolding in a chronological order that rarely traces a "linear model." A wellfunctioning innovation system has deep connections between, and a degree of codependence among, innovation stages (25). This codependence creates feedback loops across the stages of innovation.

The existence of feedback loops connecting activities in different innovation stages implies that overcoming barriers (or "blocking mechanisms") (26) to innovation in any one stage often requires looking beyond that particular stage. For example, ceramic pot filters (CPFs) offer a means for users to treat available water sources in their homes in hopes of reducing the incidence of water-borne diseases. CPFs have apparent benefits, as they can be manufactured with local materials and labor. However, CPFs often lack rigorous quality control during the production process, and many areas where CPFs may be deployed do not have access to an adequate supply chain for replacement parts. Interventions to increase CPF adoption without addressing challenges encountered in the production stage are likely to face barriers to widespread use and deliver limited benefits (SI Text).

Actors that fail to recognize the importance of feedback loops often select and promote unsuitable technologies for adoption. This problem is more prevalent when outside actors are insufficiently familiar with local settings and are passionate about specific technologies (27). Where decision-making at different innovation stages is split among actors, a so-called "principal-agent problem" can arise. For example, if nongovernmental organizations (NGOs) and aid agencies do not adequately engage local communities, they may select technologies (e.g., for water treatment) on behalf of the intended users who ultimately judge the technologies to be inappropriate, thereby hindering adoption.

Development of technologies in protected niche spaces can allow for important experimentation and early-stage user interaction to build in necessary feedback $(9,28)$. For example, when designing clean biomass cookstoves for Darfur, engaging users in an early experimentation period enabled by seed funding and in-kind work resulted in 14 iterations of stove models, leading to more suitable designs for local cooking practices (29) (SI Text).

Innovation System Interventions Often Create Ripple Effects. Due to the pervasiveness of linkages in the innovation system across stages, sectors, and scales, intervening in any one part of an innovation system can create negative and positive externalities that act as ripple effects throughout the system. Maximizing inclusive well-being requires directing the appropriate level of resources toward particular areas of technological innovation in a way that fully accounts for such positive and negative externalities.

On the negative side, innovation can cause unintended consequences, particularly as technologies gain more widespread use and as unanticipated impacts emerge. For example, local policies adopted in many jurisdictions to introduce biofuels have affected global food prices (30). Maximizing inclusive well-being in this context requires considering impacts across scales.
On the positive side, innovation in one technology area can lead to "innovation spillovers" that enable more rapid improvements and new applications in other sectors (31). In this sense, when new knowledge becomes broadly accessible, it can be a global public good by laying the foundation for further innovation (32). For example, global positioning system technology was developed for defense applications, but it has been applied in other contexts, including improving the targeting of disaster relief. Promoting inclusive well-being requires supporting innovation (e.g., through public provision or collective action) in a way that considers possible positive spillovers (32).

Change in Innovation Systems Is Often Nonlinear. Like other complex adaptive systems, change in innovation systems is path dependent. Path dependence in complex adaptive systems involves two mutually reinforcing phenomena: tipping points and lock-in. Thresholds perpetuate "locked-in" technological regimes until a "tipping point" is crossed, creating an irregular burst of technological change (33). These regime-altering bursts are exemplified by past inventions, such as the steam engine, high-yield staple crops, antibiotics, the printing press, and the internet. Each example featured the widespread utilization of a new invention, rich follow-on innovation, and broad societal change (34).

Locked-in technological regimes create time lags in how technological innovation can improve inclusive well-being. Lock-in occurs through reciprocal feedback loops, such as increasing returns to an initially adopted technology through continuous adaptation and refinement (35). Lock-in can also occur when powerful actors, who may have the most to lose from changes to the status quo, bias the institutions governing innovation systems to meet their preferences and reinforce their positions of power. Technologies in capital-intensive and infrastructure-dependent sectors are often faced with the lock-in challenge. One example is the replacement of fossil fuels with renewable energy, in which economies of scale, powerful incumbent firms, a long history of incremental technological improvement, and the long life of physical and institutional supporting infrastructure have given economic and political advantages to incumbent technologies (36).

Harnessing technological innovation for sustainable development requires designing interventions that intentionally break lock-in by crossing some tipping points (e.g., escaping from "poverty traps") (37), managing the transition to technological regimes where tipping points have already been crossed but only for some populations (e.g., increasing access for poor farmers to the technological outcomes of the "Green Revolution"), and creating lock-in to desired regimes by raising barriers to avoid other tipping points altogether (e.g., promoting climate adaptation to avoid catastrophic impacts of climate change).

\section{Understanding the Socio-Technical Nature of Innovation Systems}

Understanding innovation systems requires the integration of social and technical considerations. In innovation systems, society and technology are inextricably linked: actors shaped by institutions in society choose to pursue certain forms of knowledge and technologies, just as the knowledge that is discovered and the technologies that are developed modify and (de)legitimize the institutions of society. This reciprocal process is referred to as "coproduction" (38-40).

Socio-Technical Characteristics Can Diagnose Barriers to Innovation. To understand the full range of factors influencing technological change, actors intervening in innovation systems 
must grapple with this inextricable linkage of technology and society. A rich conceptual literature on socio-technical systems has emerged from the exploration of such connections $(15,24,33$, 40). However, due to the idiosyncratic characteristics of local contexts, this literature has struggled to provide practical guidance about the barriers to innovation that are likely to arise under a particular set of intertwined technical and social parameters. The growing body of empirical evidence on the performance of innovation systems in many different settings, combined with this already rich conceptual literature, is nonetheless beginning to inform generalizable hypotheses of practical utility. In particular, it is increasingly possible to predict that under conditions characterized by certain socio-technical characteristics (STCs), specific barriers to innovation are especially likely to emerge and thus merit close attention by innovation advocates. * Our experience suggests that the prospects for developing such useful generalizations can be greatly enhanced by drawing on cases and experiences spanning multiple sectors with common STCs, rather than drawing strictly from one sector, location, or actor group. Fully realizing this learning potential, however, will require a deepened commitment of scholars and practitioners to enrich existing conceptual frameworks with new empirical studies from an even wider diversity of contexts across space and time.

In the remainder of this section, we illustrate how an inductive STC-focused perspective on innovation systems can help diagnose barriers to innovation, increase the likelihood of the ex-ante identification of problems, and support learning from previous experiences. We illustrate the potential of an STC-focused perspective with three specific STCs that exhibit empirical associations with barriers to innovation: the presence of positive network externalities, perceptions of mundaneness, and modularity.

STC: Presence of positive network externalities. The presence of positive network externalities is an STC that describes the degree to which the adoption of a particular technology by some increases the benefits from using the technology for others (42). Users of technologies with network externalities benefit more as the total number of users increases.

Network externalities are likely to slow the initial adoption of a technology, as the incremental benefits to adoption remain low until a robust peer network forms. Hence, network externalities create a paradoxical barrier at this innovation stage: many potential users would be inclined to adopt the technology if only others had already adopted it. If initial adoption barriers can be overcome, technologies with network externalities may also face barriers in the retirement stage, as such technologies tend to face lock-in (35). Lock-in for technologies with network externalities can occur if barriers to timely retirement arise from users who find switching to other technologies without established networks less attractive than remaining with the current technology already used by their peers. Overcoming the barriers to network externalities may require the provision of incentives to overcome the initial cost of adopting a new technology and encourage enough early adoption to achieve critical mass.

The presence of positive network externalities is exemplified by the case of industrial symbiosis, a practice to configure

\footnotetext{
*This general effort to relate certain socio-technical characteristics to subsequent innovation system dynamics dates back at least to the classic work of Hayami and Ruttan who concluded that labor-saving agricultural technologies would prosper in social conditions where labor was scarce, whereas technologies that made profligate use of labor would prosper in conditions where labor was plentiful (41).
}

industrial technologies in a manner that reduces the overall impact of manufacturing by linking wastes and byproducts in one process to the input needs of another (43). The Tianjin EconomicTechnological Development Area Low-Carbon Economy Promotion Center (EcoTEDA) program in Tianjin, China, is an example of an industrial symbiosis model where increasing the number of users would greatly expand the value of the network. Although a larger network would enhance the quantity and robustness of possible resource exchanges between participating firms, developing a self-sustaining network of peers de novo in the EcoTEDA program has been challenging. The paradoxical barrier to initial adoption was overcome in the EcoTEDA case through an active program of firm engagement that demonstrated the value of joining the program's network combined with financial and regulatory incentives, such as government subsidies for participation in the program database and use of an eco-logo (SI Text).

STC: Perceptions of mundaneness. Perceptions of the mundaneness of a technology is an STC that describes the degree to which a technology fails to hold the attention of key actors in an innovation system, especially actors who play important roles in technology invention and selection. Technologies that draw on simpler scientific principles or approaches tend to be perceived as mundane. However, mundaneness is fundamentally determined by social perceptions, including whether a technology is considered novel or whether it fits into preexisting conceptions of technological value.

Perceptions of the mundaneness of a technology tend to shift the mobilization of resources away from these technological options, discounting their appropriateness or effectiveness (44). The mundaneness STC cautions practitioners to be self-aware of institutional influences and social expectations that create perceptions that unduly restrict the solution set of technologies they consider in the selection stage.

The role of mundaneness is exemplified by the development of the system of rice intensification (SRI) in Madagascar. In the case of SRI, established research centers working on high-yield, drought-tolerant seed varieties were initially skeptical of the benefits of the SRI technology, which they perceived to be a mundane practice-based approach for improving rice yields. Instead, they preferred modern laboratory techniques for developing new hybrid and genetically modified crops. This bias against mundane technologies led much of the established research community to downplay a potentially useful technology for helping small farmers (SI Text).

STC: Level of modularity. The level of modularity is an STC that describes the degree to which a technology is comprised of design elements that are easily disaggregated and organized according to a formal architecture or plan (45). A modular technology can therefore change via innovation in a subset of its components that are later reintegrated into the whole without complete redesign of the technology's architecture.

More modular technologies have lower barriers to adaptation because the separability of components allows actors to improve one component without the architectural knowledge of the entire technology (46). Modularity lowers the costs of adaptation and expands the range of actors who can engage in adapting a technology. As a result, entrepreneurial actors may expand the settings in which a modular technology is suitable, thereby serving a wider array of human needs.

Modularity is exemplified by the case of cookstoves for Darfur and Ethiopia. After some success in supporting the adoption of the Berkeley Darfur cookstove in Darfur, Sudan, the Berkeley cookstove team sought to adapt the stove to expand deployment 
to Ethiopia. The cookstove was initially designed in a modular fashion, such that the shell of the stove (manufactured in India) could be maintained while the internal pot supports could be separately modified to enable the use of culturally and geographically specific cooking vessels (SI Text).

The three STCs presented here exemplify a broad range of potentially useful diagnostic STCs and are thoroughly supported by evidence in the academic literature (as referenced above) and are exemplified in the longer discussion of cases in SI Text. However, these three STCs are certainly not the only ones that have analytic value or even the most important ones for making technological innovation work for sustainable development. The list of useful STCs is growing. ${ }^{\dagger}$ Extending the list and refining understanding of its elements are important tasks for sustainability science. The examples presented here highlight the potential utility of an STC-focused approach for helping practicing scientists, engineers, entrepreneurs, and policy advocates diagnose potential barriers that may limit the actual contribution of technology to sustainable development.

Socio-Technical Characteristics Facilitate Learning Across Innovation Systems. Practitioners with a stake in advancing sustainable development usually have direct access to a limited set of experiences from which to develop evidence-based policy and action strategies. Too often, practitioners struggle to make innovation work for a particular need because they fail to learn from the experience of others. This failure stems from a lack of interactions between actors working in different fields and settings, creating siloes of narrowed expertise (48). As a result, there is a lost opportunity that the identification of cross-sectoral STCs can help address.

An STC-focused perspective can enable the ex-ante identification of innovation system barriers by identifying generalizable diagnoses of barriers. Evidence for the generalizability of such diagnoses rests on the breadth of experience that affirms relationships between STCs and barriers. In discussion of example STCs above, we illustrate how perceptions of mundaneness in the SRI case explain barriers in the selection stage of innovation. This relationship also holds in the case of ceramic pot filters. In this case, unlike the SRI case, many funding groups promoted the CPF technology because it was connected to an appealing story where local potters could be empowered to build low-cost water filters with local materials. However, these perceptions of ceramic filters at times unduly shifted attention away from other water treatment technologies perceived to be mundane because they were already sold in the market and known to local actors (SI Text). The relationship between specific STCs and barriers exemplified in these two cases suggests that new cases in which a technology is perceived to be mundane may also face similar selection barriers. However, as with any inductive approach, new empirical evidence may require reassessment and adjustment to the relationships described.

An STC-focused perspective can also enable learning across sectors to improve the design of innovation system interventions. We illustrate this by drawing potential lessons for the agriculture sector from efforts in the health sector to make the price of artemisinin-based combination therapy (ACT) for malaria treatment affordable for rural populations in sub-Saharan Africa and Southeast Asia. A group of global health funding organizations created a

${ }^{\dagger} \mathrm{A}$ more extensive, but still incomplete, list of STCs is presented in Anadon et al. (47). global subsidy called the Affordable Medicines Facility-malaria (AFMm), which reduced the price of ACTs to end users. Manufacturers received the global subsidy directly and then shipped reduced-price drugs to countries. They were then supplied into informal village-level supply chains at a cost competitive with less desirable treatment options. Three STCs are important in the ACT case: end users who have limited financing and information, a high price of the technology relative to inferior alternatives, and lengthy transnational supply chains between manufacturers and end users (SI Text). These same three STCs are also relevant to efforts to make drought-tolerant seed varieties broadly accessible. The shared STCs of these two seemingly unrelated cases suggest that an intervention similar to the ACT subsidy could be considered to address the need for more affordable drought-tolerant seed varieties for farmers in developing countries.

We conclude that the community of scholars and practitioners seeking to make innovation work for sustainable development would be well served by an effort to build up a larger set of STCs, develop insights derived from their application, and use the resulting list as a set of heuristics to improve diagnosis of barriers. Expanding knowledge about the set of STCs would challenge, deepen, and extend the nascent theory-building on how sociotechnical linkages affect innovation dynamics.

Understanding Institutional Change in Innovation Systems Institutions shape the functioning of innovation systems by guiding and constraining the activities of actors at multiple scales, ranging from customs that extend no further than a particular village, to regional or national laws, to codified norms in international treaties (17). These multiscale institutions are often not aligned to guide technological innovation toward sustainable development goals. However, actors can change institutions to reorient innovation systems toward sustainable development.

Institutions Are Not Necessarily Aligned Toward Sustainable Development. The complex web of existing institutions governing innovation systems reflects existing power structures. Often, existing institutions are not aligned with sustainable development goals due primarily to three factors. First, existing institutions tend to drive innovative activity toward the areas of greatest financial prospect rather than the areas of greatest human need. Economic incentives propel much innovation to meet the needs of those who can exert "market" or "demand pull" (49) but not those with few financial resources. The problems of neglected diseases and neglected crops, for which few new technologies have been developed, exemplify such gaps.

Second, existing institutions do not adequately govern activities producing negative externalities mediated over environmental systems or over long time horizons. For example, private actors can often degrade ecosystems on which human well-being depends without consequence. In the case of industrial symbiosis in Tianjin, China, private incentives were insufficient to drive firms to participate in the EcoTEDA industrial symbiosis network that would have lowered overall environmental impacts; additional financial and regulatory incentives to reduce waste and emissions were required (SI Text).

Third, the public-good nature of the knowledge that enables innovation and is embodied in particular technologies has led to the creation of institutions restricting the dissemination of knowledge to strengthen incentives for investing in its creation. The intellectual property (IP) regime is an institution that aims to incentivize innovation by allowing inventors to exclude others from 
using patented technology for a fixed period, during which they can charge monopoly prices for patented products or earn revenues from licensing. Although the IP regime strengthens incentives to invest resources in invention, it also restricts the use of new knowledge by raising prices or blocking follow-on innovation (50, 51). It has been argued that the increasingly globalized IP regime will diminish prospects for technology transfer and competition in developing countries, particularly for several important technology areas related to meeting sustainable development needs (52).

These three areas of shortcoming of innovation systems highlight the need for institutional reform.

Innovation Systems Involve Many Actors Operating at Different Stages and Scales. Reforming institutions to better align innovation systems with sustainable development requires mobilizing collective action across a complex and large set of actors who work at many scales and who engage in activities that overlap and sometimes conflict $(53,54)$. The interdependencies of actors may be explicit, such as through technology commercialization licensing agreements that involve a formal contract transferring intellectual property (55). Alternatively, linkages connecting actors may be implicit, such as the underemphasized dependence of new product development by many computer hardware and pharmaceutical firms on prior government-funded $R \& D(56,57)$. Collective action problems arise because actors operating across different stages and scales vary in their interests and incentives and are not necessarily driven by the goal of sustainable development. For example, a national government usually has little motivation to take into account the needs of citizens beyond its borders, a profit-maximizing firm lacks incentives to invent technologies for people who cannot afford its products, and consumers lack the impetus to consider how their decisions impact other communities distant in time or space.

Aligning actors working at different scales of the innovation system is challenging. The problem is particularly relevant when needs that vary at the local scale are not fully incorporated into decision-making elsewhere. For example, in efforts over the last few decades to promote the development and adoption of cleaner and more efficient cookstoves, inventors and selectors of technologies were often not fully engaged in local contexts and lacked an adequate understanding of the needs of end users. Many stove designs promoted by transnational actors proved unsuitable for the preparation of local dishes, which led to significant barriers in achieving widespread adoption (58) (SI Text).

Transnational institutions to drive technological innovation for sustainable development remain relatively weak or absent altogether, and national policies offer only patchwork solutions. At a national scale, policymakers regularly reshape institutions to meet national interests, such as increasing domestic economic growth, improving national security, or enhancing their citizens' well-being. National actors may develop public policies to promote innovation to advance these interests, such as subsidizing R\&D or creating publicly funded research laboratories. However, many sustainable development challenges and their potential solutions have important transnational dimensions. For example, the control of carbon emissions, the spread of infectious diseases, and the depletion of shared water resources are areas where both problems and solutions involve multiple nation-states. To meet key sustainable development challenges, greater alignment of institutions with sustainable development goals is needed at all decision-making scales.

Actors Can Change Institutions to Reorient Innovation Systems Toward Sustainable Development. The rules and norms that shape innovation systems are not necessarily aligned toward sustainable development. However, although institutions constrain actor behavior in the short term, institutions are not immutable. The incentives, capabilities, and needs of actors that comprise innovation systems coevolve with governing institutions $(13,59$, 60). Therefore, although the power of actors depends on institutions, institutions themselves are shaped by actors and can change in both incremental and radical ways (20). For example, in the early 2000s, efforts to expand access to treatment for HIV/ AIDS were hindered by stringent international IP rules that blocked developing countries from using lower-cost generic versions of HIV drugs. A global network of civil society, developing country governments, and health experts challenged the moral acceptability of these IP rules and succeeded in changing norms to allow for much greater flexibility in how patents on medicines were managed in resource-poor settings (61).

Institutions are inherently "sticky." Changing the institutions shaping innovation systems is a daunting task that requires leveraging multiple types of power, such as normative power to challenge the ethical acceptability of existing institutions; convening power to bring actors together to establish new goals, priorities, and agendas; legal power to negotiate and revise norms, binding rules, and standards; informational power to identify alternatives and to assess their feasibility; and financial power to create incentives, implement costly new policies, and reduce the risk or cost of doing so (62).

Here, we provide three examples, each detailed in SI Text, of how actors have induced institutional change to promote innovation for sustainable development. In the case of drip irrigation, government officials in Andhra Pradesh (AP), India designed a subsidy that reduced costs and incentivized private companies to market and disseminate knowledge of drip irrigation, a technology that could improve yields but was too expensive for most farmers in AP. Using its legal power to change the rules shaping the behavior of private firms and its financial power via a subsidy to implement the new rules, the government reshaped institutions to spur widespread use of drip irrigation. In contrast, in the case of SRI, a loose network of activists, lacking both legal and financial power, relied on informational and convening power to build a coalition of support for SRI. Finally, in the case of ACTs, NGOs and academics exercised normative power through a public advocacy campaign to challenge the then-prevailing norm that donors should not subsidize relatively expensive medicines for lower-income populations.

In sum, without greater effort by practitioners, policymakers, and scholars, sustainable development will not become a strong enough organizing principle to align actor behavior in most innovation systems. Realigning innovation systems toward sustainable development requires mobilizing the multiple types of power available to change institutions at all stages of innovation systems, from invention through widespread use and retirement, and at multiple scales, from local to global.

\section{Conclusion}

Technological innovation has played a central role in achieving important societal objectives, such as economic growth and improved human well-being. However, innovation systems, driven primarily by markets and the most highly resourced actors, are characterized by pervasive power imbalances. As a result, the needs of impoverished, marginalized, and future populations are not adequately met. Reorienting innovation systems toward sustainable development will require addressing power imbalances and transforming many of the deeply embedded institutions that limit innovation systems from delivering on their potential. 
We offer three recommendations for action derived from the insights presented here, deepening and extending recommendations regarding knowledge systems more generally (63).

First, measures are needed to regularize learning across spheres of practice to improve understanding of how to reorient innovation systems toward sustainable development. Understanding innovation systems and their socio-technical nature is a necessary precondition for the development of targeted interventions that realize the full potential of innovation for sustainable development. Many potential lessons are available (48), but drawing appropriate conclusions requires analytical rigor, which we believe can be facilitated by the use of STCs. Actors with convening power should facilitate learning across disparate communities of practice, for example, by organizing conferences that purposefully bring together practitioners, policymakers, and scholars working in more than one sector (e.g., the National Research Council's Roundtable on Science and Technology for Sustainability) (64). Research funders should support comparative analyses that draw from the experience of more than one sector or location. Universities should teach students across disciplines to think broadly about technological innovation, and not only innovation in a single sector, region, or technology area. More broadly, practitioners should use STCs as heuristics to identify possible barriers to innovation that could emerge with certain innovation system interventions.

Second, power disparities can be mitigated by identifying ways to systematically take into account the interests of underserved populations throughout the innovation process. Because impoverished and future populations often lack the power needed to influence innovation systems, problems arise such as third-party selection of technologies poorly suited for end users. There is also untapped potential for end users to adapt technologies for use in new settings (28). Building in channels of communication between underserved populations and powerful actors would help alleviate power disparities and strengthen the feedback loops that characterize well-functioning innovation systems. We propose that actors with convening power and normative authority should identify ways to more meaningfully engage marginalized populations in innovation systems (65). For example, international NGOs and United Nations agencies can directly engage marginalized populations when negotiating norms and establishing priorities rather than speaking on behalf of directly affected populations. We also argue for capacity building among less powerful populations to represent their interests in global forums. The gradual shift in the multilateral climate regime to policies that more deeply engage developing country governments and firms demonstrates that such change is possible. Previously, international organizations primarily focused on technology transfer, often through financing arrangements to export technology from more advanced countries to developing countries. However, newer forms of cooperation seek to more deeply engage developing country actors in the process of technology invention and selection by reducing information asymmetries, decreasing social distance between actors with expertise and skills, and fostering new collaborative R\&D arrangements (66).
Finally, we argue that actors should reform institutions to reorient innovation systems toward sustainable development in a way that considers all stages of innovation and all relevant scales at the outset. To illustrate: reform efforts in the biomedical innovation system previously focused on just one innovation stage, such as driving invention for neglected diseases or decreasing the price of HIV/AIDS medicines. More recently, institutional reforms under consideration involve using publicly financed "push" and "pull" incentives simultaneously to steer inventive activity toward priority diseases while building affordability measures into R\&D processes from their inception. Governments of both industrialized and developing countries are being asked to contribute to a global biomedical R\&D fund for this purpose (67), an illustration of reforming institutions simultaneously at both national and global scales.

In the context of climate change mitigation, institutional reform to create a carbon price through regional, national, and subnational carbon markets has shifted the incentives facing consumers and producers toward low-carbon forms of energy at all stages of innovation. For example, carbon pricing increases the profitability of private action to invest in renewable energy invention, select more energy-efficient appliances, and hasten the retirement of greenhouse gas-intensive power plants. However, carbon pricing alone may be inadequate for addressing climate change in a cost-effective manner. Doing so also requires further strengthening incentives for private energy R\&D and concerted public R\&D investment (68).

Many types of interventions are needed to shift the trajectories of specific technologies toward sustainable development, requiring actors to leverage the different types of power available to them. Shifting entire regimes toward sustainability is even more challenging (10). Altering the institutions governing innovation systems may appear politically or practically impossible in the short run. However, without institutional change, certain populations will remain excluded from the benefits of innovation, and the interests of present generations will continue to unfairly outweigh those of the future. Making technological innovation work for sustainable development requires making fundamental changes to the rules of the game.

\section{Acknowledgments}

We thank the many researchers who contributed case studies and background papers to the project and provided helpful feedback: Ahmed Abdel Latif, Dwayne Appleby, Kathleen Araujo, Françoise Bichai, Kayje Booker, Hyundo Choi, Sharon Davis, Brian Dillon, Kristian Dubrawski, Stephen Elliott, Ram Fishman, Lonia Friedlander, Arani Kajenthira Grindle, Ben Hurlbut, Christina Ingersoll, Erin Kempster, Daniele Lantagne, Laura Pereira, Polina Ponce de Leon, John-Arne Röttingen, Daniel Shemie, Lucilla Spini, Jennie Stephens, Vanessa Timmer, Livio Valenti, Lee Vinsel, Mark Williams, Paul Wilson, and Alyssa Yamamoto. We are grateful for the useful feedback received from participants at a workshop sponsored by the Weatherhead Center for International Affairs at Harvard University in April 2014; to the participants at a workshop at University College London in May 2016 cosponsored by the Sustainability Science Program at Harvard and the Department of Science, Technology, Engineering, and Public Policy at University College London; and to the reviewers and editor who handled the paper at PNAS. The foundation for this paper was developed over the course of a multiyear research project on Innovation and Access to Technologies for Sustainable Development based at the Harvard Kennedy School (HKS). It was supported by the Sustainability Science Program at HKS and Italy's Ministry for Environment, Land, and Sea, with contributions from the Science, Technology, and Public Policy Program of the HKS Belfer Center for Science and International Affairs.

1 WCED (1987) Report of the World Commission on Environment and Development: Our Common Future (Oxford Univ Press, Oxford).

2 Arrow KJ, Dasgupta P, Goulder LH, Mumford KJ, Oleson K (2012) Sustainability and the measurement of wealth. Environ Dev Econ 17(3):317-353.

3 Dasgupta P (2001) Human Well-Being and the Natural Environment (Oxford Univ Press, New York).

4 World Bank, ed (2011) The Changing Wealth of Nations: Measuring Sustainable Development in the New Millennium (World Bank, Washington, DC).

5 UNU-IHDP UNEP (2014) Inclusive Wealth Report 2014: Measuring Progress Toward Sustainability (Cambridge Univ Press, Cambridge, UK). 
6 Brooks H (1980) Technology, evolution, and purpose. Daedalus 109(1):65-81.

7 Lundvall B-Å (2010) National Systems of Innovation: Toward a Theory of Innovation and Interactive Learning (Anthem Press, London).

8 Nelson R (1993) National Innovation Systems: A Comparative Analysis (Oxford Univ Press, New York).

9 Geels FW, Schot J (2010) The dynamics of transitions: a socio-technical perspective-a multi-level perspective on transitions. Transitions to Sustainable Development: New Directions in the Study of Long Term Transformative Change, eds Grin J, Rotmans J, Schot J (Routledge, New York), pp 18-28.

10 Grin J, Rotmans J, Schot J, eds (2010) Transitions to Sustainable Development: New Directions in the Study of Long Term Transformative Change (Routledge, New York).

11 Pedrique B, et al. (2013) The drug and vaccine landscape for neglected diseases (2000-11): a systematic assessment. Lancet Glob Health 1(6):e371-e379.

12 Nemet GF, Kammen DM (2007) US energy research and development: Declining investment, increasing need, and the feasibility of expansion. Energy Policy 35(1):746-755

13 Malerba F (2002) Sectoral systems of innovation and production. Res Policy 31(2):247-264.

14 Binz C, Truffer B, Coenen L (2014) Why space matters in technological innovation systems—mapping global knowledge dynamics of membrane bioreactor technology. Res Policy 43(1):138-155.

15 Hekkert MP, Suurs RAA, Negro SO, Kuhlmann S, Smits REHM (2007) Functions of innovation systems: A new approach for analysing technological change. Technol Forecast Soc Change 74(4):413-432.

16 Geels FW (2004) From sectoral systems of innovation to socio-technical systems. Res Policy 33(6-7):897-920.

17 Markard J, Truffer B (2008) Technological innovation systems and the multi-level perspective: Towards an integrated framework. Res Policy 37(4):596-615.

18 Martin BR (2016) Twenty challenges for innovation studies. Sci Public Policy 43(3):432-450.

19 Krasner SD (1982) Structural causes and regime consequences: Regimes as intervening variables. Int Organ 36(2):185-205

20 North DC (1990) Institutions, Institutional Change and Economic Performance (Cambridge Univ Press, Cambridge, UK).

21 March JG, Olsen JP (2006) The logic of appropriateness. The Oxford Handbook of Public Policy, eds Moran M, Rein M, Goodin R (Oxford Univ Press, Oxford), pp 689-708.

22 Johnson B (2010) Institutional learning. National Systems of Innovation: Toward a Theory of Innovation and Interactive Learning, ed Lundvall B (Anthem Press, London), pp 23-46.

23 Grubler A, et al. (2012) Policies for the Energy Technology Innovation System (ETIS). Global Energy Assessment: Toward a Sustainable Future (Cambridge Univ Press and the International Institute for Applied Systems Analysis, New York), pp 1665-1744.

24 Bijker WE, Hughes TP, Pinch TJ, eds (2012) The Social Construction of Technological Systems: New Directions in the Sociology and History of Technology (MIT Press, Cambridge, MA).

25 Kline SJ, Rosenberg N (1986) An overview of innovation. The Positive Sum Strategy: Harnessing Technology for Economic Growth, eds Landau R, Rosenberg N (National Academy Press, Washington, DC), p 290.

26 Bergek A, Jacobsson S, Carlsson B, Lindmark S, Rickne A (2008) Analyzing the functional dynamics of technological innovation systems: A scheme of analysis. Res Policy 37(3):407-429

27 Vaubel R (2006) Principal-agent problems in international organizations. Rev Int Organ 1(2):125-138.

28 Lebel L, Lorek S (2008) Enabling sustainable production-consumption systems. Annu Rev Environ Resour 33:241-275.

29 Booker KM, Gadgil AJ, Winickoff DE (2012) Engineering for the global poor: The role of intellectual property. Sci Public Policy 39(6):775-786.

30 Zilberman D, Hochman G, Rajagopal D, Sexton S, Timilsina G (2013) The impact of biofuels on commodity food prices: Assessment of findings. Am J Agric Econ 95(2):275-281.

31 Griliches Z (1992) The search for R\&D spillovers. Scand J Econ 94:S29-S47.

32 Stiglitz JE (1999) Knowledge as a global public good. Glob Public Goods 1(9):308-326.

33 Geels FW (2002) Technological transitions as evolutionary reconfiguration processes: A multi-level perspective and a case-study. Res Policy 31(8-9):1257-1274.

34 Advisory Committee for Environmental Research and Education (2009) Transitions and Tipping Points in Complex Environmental Systems (NSF, Washington, DC).

35 Arthur WB (1989) Competing technologies, increasing returns, and lock-in by historical events. Econ J 99(394):116-131.

36 Unruh GC (2000) Understanding carbon lock-in. Energy Policy 28(12):817-830.

37 Sachs J (2005) The End of Poverty: Economic Possibilities for Our Time (Penguin Books, New York).

38 Murmann JP (2003) Knowledge and Competitive Advantage: The Coevolution of Firms, Technology, and National Institutions (Cambridge Univ Press, New York).

39 Trist E (1981) The evolution of socio-technical systems as a conceptual framework and as an action research program. Perspectives on Organization Design \& Behavior, eds Van de Ven A, Joyce W (John Wiley \& Sons, New York), pp 19-75.

40 Jasanoff S, ed (2010) States of Knowledge: The Co-Production of Science and Social Order (Routledge, London).

41 Hayami Y, Ruttan WW (1985) Agricultural Development: An International Perspective (Johns Hopkins Univ Press, Baltimore).

42 Katz ML, Shapiro C (1985) Network externalities, competition, and compatibility. Am Econ Rev 75(3):424-440.

43 Lombardi DR, Lyons D, Shi H, Agarwal A (2012) Industrial symbiosis. J Ind Ecol 16(1):2-7.

44 Borup M, Brown N, Konrad K, Van Lente H (2006) The sociology of expectations in science and technology. Technol Anal Strateg Manage 18(3-4):285-298.

45 Baldwin CY, Clark KB (2006) Modularity in the design of complex engineering systems. Complex Engineered Systems, eds Braha D, Minai AA, Bar-Yam Y (Springer, Berlin), pp 175-205.

46 Henderson RM, Clark KB (1990) Architectural innovation: The reconfiguration of existing product technologies and the failure of established firms. Adm Sci $Q$ 35(1):9-30.

47 Anadón LD, et al. (2014) Innovation and access to technologies for sustainable development: Diagnosing weaknesses and identifying interventions in the transnational arena. Sustainability Science Program Working Paper No. 2014-01 (Harvard Kennedy School of Government, Cambridge, MA). Available at https://www.hks.harvard.edu/centers/mrcbg/programs/sustsci/documents/papers/2014-01.

48 Bell DE, Clark WC, Ruttan WW (1994) Global research systems for sustainable development: Agriculture, health, and environment. Agriculture, Environment, and Health: Sustainable Development in the 21st Century, ed Ruttan VW (Univ Minnesota Press, St. Paul), pp 358-379.

49 Mowery D, Rosenberg N (1979) The influence of market demand upon innovation: A critical review of some recent empirical studies. Res Policy 8(2):102-153.

50 Stiglitz JE (2008) Economic foundations of intellectual property rights. Duke Law J 57(6):1693-1724.

51 David PA (1993) Intellectual property institutions and the panda's thumb: Patents, copyrights, and trade secrets in economic theory and history. Global Dimensions of Intellectual Property Rights in Science and Technology, eds Wallerstein M, Mogee M, Schoen R (National Academy Press, Washington, DC), pp $19-62$.

52 Maskus KE, Reichman JH (2004) The globalization of private knowledge goods and the privatization of global public goods. J Int Econ Law 7(2):279-320.

53 Alter KJ, Meunier S (2009) The politics of international regime complexity. Perspect Polit 7(1):13-24.

54 Keohane RO, Victor DG (2011) The regime complex for climate change. Perspect Polit 9(1):7-23.

55 Arora A, Fosfuri A, Gambardella A (2004) Markets for Technology: The Economics of Innovation and Corporate Strategy (MIT Press, Cambridge, MA).

56 Mazzucato M (2014) The Entrepreneurial State: Debunking Public vs. Private Sector Myths (Anthem Press, London), Revised Ed.

57 Sampat BN, Lichtenberg FR (2011) What are the respective roles of the public and private sectors in pharmaceutical innovation? Health Aff (Millwood) 30(2): 332-339.

58 World Bank (2011) Household Cookstoves, Environment, Health, and Climate Change: A New Look at an Old Problem (The International Bank for Reconstruction and Development, The World Bank, Washington, DC). 
59 Carlsson B, Stankiewicz R (1991) On the nature, function and composition of technological systems. J Evol Econ 1(2):93-118.

60 Edquist C (2005) Systems of innovation: Perspectives and challenges. Oxford Handbook of Innovation, eds Fagerberg J, Mowery D (Oxford Univ Press, Oxford), pp 181-208.

61 Hoen E, Berger J, Calmy A, Moon S (2011) Driving a decade of change: HIV/AIDS, patents and access to medicines for all. J Int AIDS Soc 14(1):15.

62 Barnett MN, Duvall R, eds (2005) Power in Global Governance (Cambridge Univ Press, Cambridge, UK).

63 Clark WC, van Kerkhoff L, Lebel L, Gallopin GC (2016) Crafting usable knowledge for sustainable development. Proc Natl Acad Sci USA 113(17):4570-4578.

64 Clark W, Holliday L (2006) Linking Knowledge with Action for Sustainable Development: The Role of Program Management-Summary of a Workshop (National Academies Press, Washington, DC).

65 van Kerkhoff L, Lebel L (2006) Linking knowledge and action for sustainable development. Annu Rev Environ Resour 31:445-477.

66 Ockwell D, Sagar A, de Coninck H (2015) Collaborative research and development (R\&D) for climate technology transfer and uptake in developing countries: Towards a needs driven approach. Clim Change 131(3):401-415.

67 WHO (2016) Health Product Research and Development Fund: A Proposal for Financing and Operation (Special Programme for Research and Training in Tropical Diseases, Geneva).

68 Jaffe AB, Newell RG, Stavins RN (2005) A tale of two market failures: Technology and environmental policy. Ecol Econ 54(2-3):164-174.

69 Moon S (2009) Medicines as global public goods: The governance of technological innovation in the new era of global health. Glob Health Gov 2(2).

70 Wilson P (2016) The Affordable Medicines Facility for Malaria: Implications for Malaria Treatment and Access to Other New Technologies (Sustainability Science Program, Harvard University, Cambridge, MA).

71 Payne D (1987) Spread of chloroquine resistance in Plasmodium falciparum. Parasitol Today 3(8):241-246.

72 Klein EY (2013) Antimalarial drug resistance: A review of the biology and strategies to delay emergence and spread. Int J Antimicrob Agents 41(4):311-317.

$73 \mathrm{Tu}$ Y (2011) The discovery of artemisinin (qinghaosu) and gifts from Chinese medicine. Nat Med 17(10):1217-1220.

74 Honigsbaum M (2001) The Fever Trail: In Search of the Cure for Malaria (Farrar, Straus and Giroux, New York).

75 Arrow KJ, Panosian C, Gelband H, Institute of Medicine (US), eds (2004) Saving Lives, Buying Time: Economics of Malaria Drugs in an Age of Resistance (National Academies Press, Washington, DC).

76 Harley A (2016) The System of Rice Intensification for Improving Rice Yields: The Hidden Role of Technology Selection for Meeting the Needs of Vulnerable Populations (Sustainability Science Program, Harvard University, Cambridge, MA).

77 de Laulanié H (1993) Le système de riziculture intensive malgache. Tropicultura 11(3):110-114.

78 Uphoff N (1999) Agroecological implications of the system of rice intensification (SRI) in Madagascar. Environ Dev Sustain 1(3):297-313.

79 Sinclair T (2004) Agronomic UFOs Waste Valuable Scientific Resources (Rice Today, Los Banos, Philippines).

80 Booker K (2016) Berkeley Darfur Cookstove: Case Study (Sustainability Science Program, Harvard University, Cambridge, MA).

81 World Health Organization (2014) Burden of Disease from Household Air Pollution for 2012 (WHO, Geneva).

82 Gadgil A, Sosler A, Stein D (2013) Stove solutions: Improving health, safety, and the environment in Darfur with fuel-efficient cookstoves. Solut J 4(1).

83 Wilson DL, et al. (2015) Comparing cookstove usage measured with sensors versus cell phone-based surveys in Darfur, Sudan. Technologies for Development, eds Hostettler S, Hazboun E, Bolay J-C (Springer International Publishing, Cham, Switzerland), pp 211-221.

84 Lawrence Berkeley National Laboratory (2015) Cookstove projects_Ethiopia. Available at cookstoves.lbl.gov/ethiopia.php. Accessed December 10, 2015.

85 Williams M, Murthy S, Lantagne D, Spini L (2016) Access to Safe Water: An Analysis of Ceramic Water Filters (Sustainability Science Program, Harvard University, Cambridge, MA).

86 Onda K, LoBuglio J, Bartram J (2012) Global access to safe water: Accounting for water quality and the resulting impact on MDG progress. Int J Environ Res Public Health 9(3):880-894.

87 UNICEF, Organización Mundial de la Salud (2009) Diarrhoea: Why Children Are Still Dying and What Can Be Done (United Nations Children's Fund, New York).

88 Clasen T (2009) Scaling Up Household Water Treatment Among Low-Income Populations (WHO, Geneva).

89 Lantagne D (2001) Investigation of the Potters for Peace colloidal silver impregnated ceramic filter-Report 1: Intrinsic effectiveness. Available at web.mit.edu/ watsan/Docs/Other\%20Documents/ceramicpot/PFP-Report1-Daniele\%20Lantagne,\%2012-01.pdf. Accessed July 8, 2016.

90 Potters for Peace (2015) Our common language is clay. Available at pottersforpeace.com/. Accessed December 16, 2015

91 Corbett S (2008) Solution in a pot. NY Times Mag, p MM38.

92 Brown J, Chai R, Wang A, Sobsey MD (2012) Microbiological effectiveness of mineral pot filters in Cambodia. Environ Sci Technol 46(21):12055-12061.

93 Brown J, Sobsey M (2006) Independent Appraisal of Ceramic Water Filtration Interventions in Cambodia: Final Report. Available at www.potterswithoutborders. com/wp-content/uploads/2012/12/Brown_and_Sobsey_2006_-_UNICEF_ceramic_filter_final_report.pdf. Accessed July 8, 2015.

94 Lantagne D (2001) Investigation of the Potters for Peace colloidal silver impregnated ceramic filter-Report 2: Field investigations. Available at web.mit.edu/ watsan/Docs/Other\%20Documents/ceramicpot/PFP-Report2-Exec\%20Sum,\%20DanieleLantagne,\%2012-01.pdf.

95 Sobsey MD, Stauber CE, Casanova LM, Brown JM, Elliott MA (2008) Point of use household drinking water filtration: A practical, effective solution for providing sustained access to safe drinking water in the developing world. Environ Sci Technol 42(12):4261-4267. Accessed July 8, 2016.

96 UNICEF (2007) Improving Household Drinking Water Quality: Use of Ceramic Water Filters in Cambodia (UNICEF Water and Sanitation Program, Phnom Penh, Cambodia).

97 Desmyter D, Adagwine AP, Ibrahim S, Jackson MK, Murcott SE (2009) Monitoring and Evaluation of 1,000 Households Receiving Ceramic Pot (Kosim) Filters After an Emergency Flood Mass Distribution in Northern Ghana (International Ceramic Pot Filter Workshop, Atlanta).

98 Harley A, Friedlander L (2016) Innovation and Access to Technologies for Sustainable Development: A Case Study of the Drip Irrigation in India (Sustainability Science Program, Harvard University, Cambridge, MA)

99 Burney JA, Naylor RL (2012) Smallholder irrigation as a poverty alleviation tool in sub-Saharan Africa. World Dev 40(1):110-123.

100 Fischhendler I (2008) Institutional conditions for IWRM: The Israeli case. Ground Water 46(1):91-102.

101 ICID (2014) International Commission on Irrigation and Drainage: Annual Report 2013-14 (International Commission on Irrigation and Drainage, New Delhi).

102 Friedlander L, Tal A, Lazarovitch N (2013) Technical considerations affecting adoption of drip irrigation in sub-Saharan Africa. Agric Water Manage 126:125-132.

103 Palanisami K, Mohan K, Kakumanu KR, Raman S (2011) Spread and economics of micro-irrigation in India: evidence from nine states. Rev Agric 46(26 \& 27): 81-86.

104 Bhamoriya V, Mathew S (2014) An Analysis of Resource Conservation Technology: A Case of Micro-Irrigation System (Drip Irrigation) (Centre for Management in Agriculture Indian Institute of Management, Ahmedabad, India).

105 Appleby D (2016) The Industrial Symbiosis Innovation System: A Case Study (Sustainability Science Program, Harvard University, Cambridge, MA).

106 Harris S (2007) Industrial symbiosis in the Kwinana industrial area (Western Australia). Meas Control 40(8):239-244.

107 Yu C, Dijkema GP, Jong M (2014) What makes eco-transformation of industrial parks take off in China? J Ind Ecol 19(3):441-456.

108 Paquin RL, Howard-Grenville J (2012) The evolution of facilitated industrial symbiosis. J Ind Ecol 16(1):83-93.

109 Shi H, Chertow M, Song Y (2010) Developing country experience with eco-industrial parks: A case study of the Tianjin Economic-Technological Development Area in China. J Clean Prod 18(3):191-199.

110 Park H-S, Rene ER, Choi S-M, Chiu AS (2008) Strategies for sustainable development of industrial park in Ulsan, South Korea-From spontaneous evolution to systematic expansion of industrial symbiosis. J Environ Manage 87(1):1-13. 